\title{
Prospective validation of a predictive model that identifies homeless people at risk of re-presentation to the emergency department
}

\author{
Gaye Moore, BN (Hons), PhD ${ }^{\mathrm{a}, *}$, Graham Hepworth, $\mathrm{PhD}^{\mathrm{b}}$, \\ Tracey Weiland, PhDc , Elizabeth Manias, PhDd, Marie Frances Gerdtz, PhD ${ }^{d}$, \\ Margaret Kelaher, $\mathrm{PhD}^{\mathrm{e}}$, David Dunt, $\mathrm{PhD}^{\mathrm{e}}$
}

\footnotetext{
a Melbourne School of Population Health, Faculty of Medicine, Dentistry and Health Sciences, The University of Melbourne, Level 4, 207 Bouverie St, Carlton, Victoria 3010, Australia

b Statistical Consulting Centre, Department of Mathematics and Statistics, The University of Melbourne, Victoria 3010, Australia

' EPIcentre, Emergency Medicine, St Vincent's Hospital Melbourne, PO Box 2900, Fitzroy, Victoria 3065, Australia

${ }^{\mathrm{d}}$ Melbourne School of Health Sciences, Faculty of Medicine, Dentistry and Health Sciences, The University of Melbourne, Level 5 , 234 Queensberry St, Carlton, Victoria 3010, Australia

e Centre for Health Policy, Programs and Economics, Melbourne School of Population Health, University of Melbourne, 207

Bouverie St, Parkville, Victoria 3010, Australia
}

Received 23 September 2011; received in revised form 20 December 2011; accepted 22 December 2011

\author{
KEYWORDS \\ Emergency \\ department; \\ Homeless people; \\ Hospital \\ re-presentation; \\ Risk screening
}

\begin{abstract}
Summary
Objective: To prospectively evaluate the accuracy of a predictive model to identify homeless people at risk of representation to an emergency department.

Methods: A prospective cohort analysis utilised one month of data from a Principal Referral Hospital in Melbourne, Australia. All visits involving people classified as homeless were included, excluding those who died. Homelessness was defined as living on the streets, in crisis accommodation, in boarding houses or residing in unstable housing. Rates of re-presentation, defined as the total number of visits to the same emergency department within 28 days of discharge from hospital, were measured. Performance of the risk screening tool was assessed by calculating sensitivity, specificity, positive and negative predictive values and likelihood ratios.

Results: Over the study period (April 1, 2009 to April 30, 2009), 3298 presentations from 2888 individuals were recorded. The homeless population accounted for $10 \%(n=327)$ of all visits and 7\% $(n=211)$ of all patients. A total of $90(43 \%)$ homeless people re-presented to the emergency department. The predictive model included nine variables and achieved $98 \%(\mathrm{Cl}$,
\end{abstract}

\footnotetext{
* Corresponding author at: PO Box 2900, Fitzroy, Victoria 3065, Australia. Tel.: +61 039416 0000; fax: +61039416 3919.

E-mail address: dgmoore@optusnet.com.au (G. Moore).
}

1574-6267/\$ - see front matter @ 2012 College of Emergency Nursing Australasia Ltd. Published by Elsevier Ltd. All rights reserved. doi:10.1016/j.aenj.2011.12.004 
$0.92-0.99)$ sensitivity and $66 \%(\mathrm{Cl}, 0.57-0.74)$ specificity. The positive predictive value was $68 \%$ and the negative predictive value was $98 \%$. The positive likelihood ratio $2.9(\mathrm{Cl}, 2.2-3.7)$ and the negative likelihood ratio was $0.03(\mathrm{Cl}, 0.01-0.13)$.

Conclusion: The high emergency department re-presentation rate for people who were homeless identifies unresolved psychosocial health needs. The emergency department remains a vital access point for homeless people, particularly after hours. The risk screening tool is key to identify medical and social aspects of a homeless patient's presentation to assist early identification and referral.

(c) 2012 College of Emergency Nursing Australasia Ltd. Published by Elsevier Ltd. All rights reserved.

\section{What is known}

- Research shows that homeless people encounter multiple barriers to accessing health care.

- The emergency department has become a default 24 hour service that offers a place to obtain treatment for multiple health issues including drug misuse, mental illness and chronic disease, as well as complex psychosocial issues.

\section{What this paper adds}

- A defined understanding of re-presentation and homeless status underpinned by a risk screening tool has clinical relevance to assist in early recognition of risk factors and targeting specific resources.

- This risk screening tool has the capacity to clearly identify key factors that highlight risk of representation within 28 days.

\section{Introduction}

The experiences of homelessness and poverty are inextricably linked as complex co-morbidities, financial hardship and barriers to health care, creating a cycle into homelessness that is difficult to interrupt. ${ }^{1}$ The homeless population is difficult to identify and engage. People who are homeless often have multiple health issues including drug misuse, mental illness and chronic disease. ${ }^{2-4}$ Lack of appropriate housing and social support means that many are frequent users of emergency departments (EDs). ${ }^{5}$

The ED is a 24-hour service, which primarily treats people with acute illnesses and injuries. Homeless people continue to account for a significant proportion of frequent ED users despite the development of outreach and case management programs for people with complex care needs. ${ }^{6,7}$ Frequent ED users utilise a disproportionate amount of resources, ${ }^{8-13}$ placing added pressure on acute care services, exacerbating prolonged waiting times in EDs and hampering access to inpatient beds. ${ }^{14,15}$ Frequent ED users are vulnerable, ${ }^{16-19}$ have complex health care needs, ${ }^{9,16,20-26}$ and suffer higher levels of mental illness, ${ }^{27}$ injury, ${ }^{28}$ morbidity, mortality, ${ }^{21,27}$ social disadvantage $\mathrm{e}^{16,18,21,22,24}$ and homelessness 4,25 than infrequent ED users. A study conducted in an Australian ED noted the total ED presentation over two years was 64,177 with a re-presentation rate of $17.3 \%(n=11,128)$ of visits and $14.0 \%(n=5718)$ of all patients. ${ }^{29}$ The odds of re-presentation increased threefold for people who were homeless compared to those living in stable accommodation (adjusted OR 3.12; $95 \% \mathrm{CI}$ $2.86-3.40) .^{29}$

Research is needed to develop a way of identifying those people who are at risk of re-presentation to the ED to assist in early identification of health problems and referral. McCusker et al. ${ }^{30}$ tested a screening tool in the ED specifically developed for the elderly (ISAR) and found that it could be used to identify elderly patients who subsequently experience high acute care hospital utilisation as well as adverse health outcomes after presentation to the ED. This study aims to broaden the scope beyond the elderly and evaluate a predictive model that had been developed ${ }^{31}$ to identify key characteristics associated with ED re-presentation to facilitate early identification and referral.

Using a large hospital administrative dataset, we previously identified key patient characteristics associated with ED re-presentation in a homeless population and subsequently developed a risk screening tool to predict the likelihood of re-presentation to the ED within 28 days of discharge from hospital (Fig. 1). ${ }^{32}$ The aim of the present study was to examine the ability of the risk screening tool to predict risk of re-presentation to the ED using a prospective sample and to compare the ED characteristics of the prospective sample with a previous retrospective sample of homeless people.

\section{Method}

\section{Theoretical model}

The risk screening tool was underpinned by the Behavioural Model for Vulnerable Populations (BMVP) which provided understanding about the complex range of factors associated with a person's utilisation of health care services specifically for social disadvantaged populations. ${ }^{33}$ The nine variables within the tool covered all four domains of the Behavioural Model. First, age, known next of kin and pensioner status are part of the environmental influences. Second, the number of medications and drug misuse are part of functional health status. Third, the number of medical issues and mental illness are part of the health status. Fourth, community case management, presenting to another hospital within 12 months and ED discharge outcome are part of the health behaviour of the homeless person and identifies health service utilisation (Table 1). 


\section{Homeless Screening Risk of Re-Presentation}

Date: ${ }_{-}{ }^{\prime}-_{-}{ }_{-} \quad$ Pt identified by ...........

Please circle the patient's place of residence

1 Public Place 2 Crisis Accommodation 3 Boarding House/Hostel 4 Vulnerable (at risk)

Assess patient and score by circling the correct response and fill in the following scores for questions 1 to 9

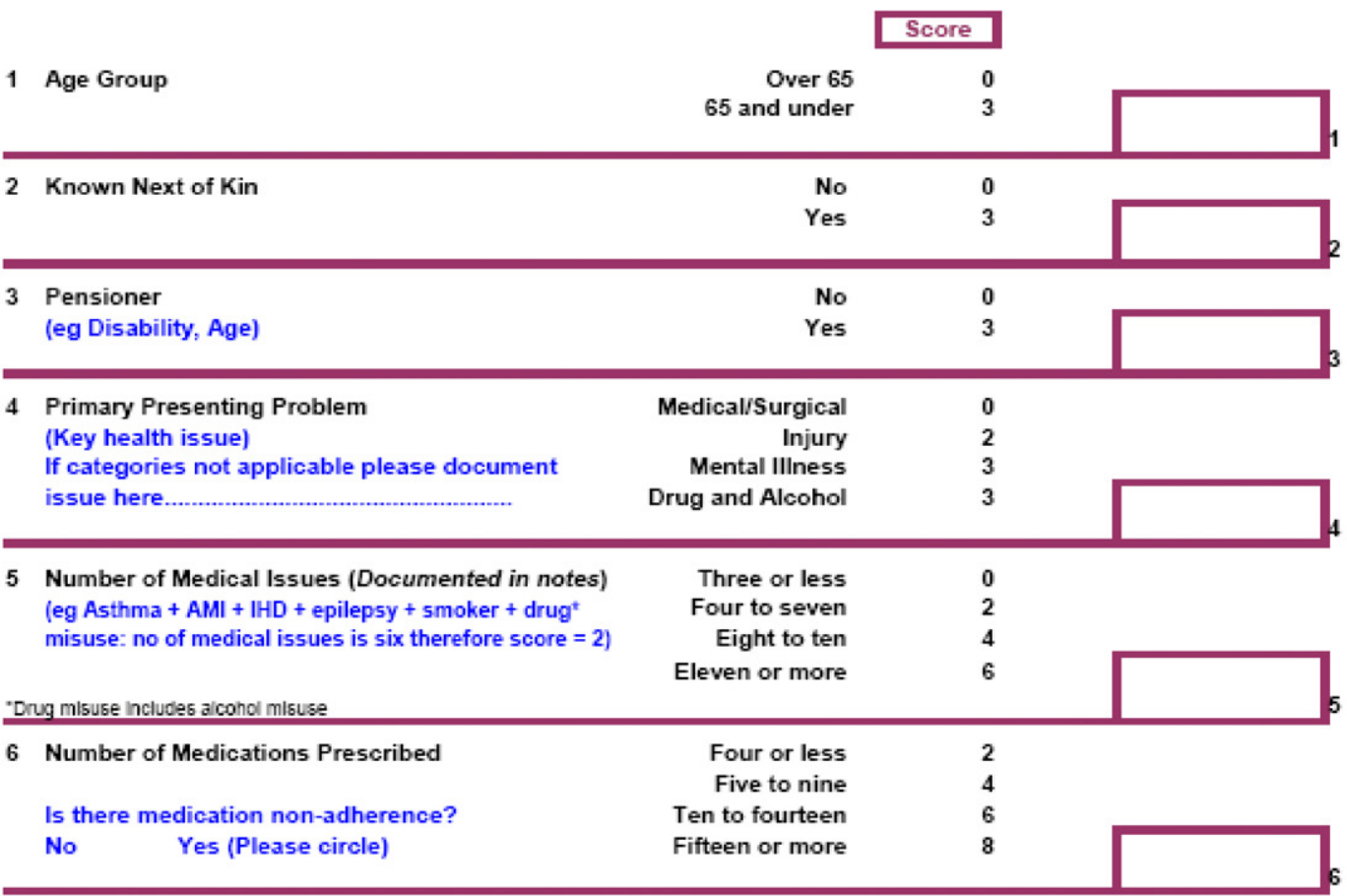

7 Community Support $\quad$ No 0

(eg RDNS HPP, HITH, D\&A, Mental Health...) Yes 3

8 Presented to Other Hospitals No $\quad$ No

(Within last 12 months) $\quad$ Yes $\quad 4$

9 Discharge Outcome Admit

Return to Ward 2

$\begin{array}{lcc}\text { Please state type of home } & \text { H.................................. Home } & 3 \\ \text { On the street } & \text { ED Admit } & 4\end{array}$

Crisis accommodation $\quad$ Transferred 5

Boarding House/Hostel Left Before Treatment 6

$\begin{array}{lll}\text { Private rental } & \text { Residential Care Facility } & 14\end{array}$

Add questions 1 to 9 and enter total risk score

0 to 13 score Low Risk 14 and over score High Risk Total Risk Scor

Please circle

Outcome of referral

No Intervention

ALERT

Referral to

Figure 1 Risk screening tool. 
Table 1 Behavioural Model for Vulnerable Populations and risk screening tool.

\begin{tabular}{|c|c|}
\hline Behavioural Model for Vulnerable Populations & Risk screening tool \\
\hline $\begin{array}{l}\text { Environmental influences } \\
\text { Predisposing domain }\end{array}$ & $\begin{array}{l}\text { Age }<65 \\
\text { Known next of kin } \\
\text { Pensioner }\end{array}$ \\
\hline $\begin{array}{l}\text { Functional health status } \\
\text { Enabling domain }\end{array}$ & $\begin{array}{l}\text { Primary presenting problem (substance misuse) } \\
\text { Number of medications }\end{array}$ \\
\hline $\begin{array}{l}\text { Health status } \\
\text { Need domain }\end{array}$ & $\begin{array}{l}\text { Primary presenting problem (mental illness) } \\
\text { Number of medical issues }\end{array}$ \\
\hline $\begin{array}{l}\text { Health behaviour } \\
\text { Health service delivery domain }\end{array}$ & $\begin{array}{l}\text { Discharge outcome } \\
\text { Presented to other hospital within } 12 \text { months }\end{array}$ \\
\hline
\end{tabular}

Source: Adapted from Gelberg et al. ${ }^{35}$

Note: Predisposing domain represents demographic and social characteristics. Enabling domain represents community financial resources.

Need domain represents health status.

\section{Tool development and description using a retrospective database}

The development of the tool utilised in this study is outlined in Table 2. The coefficient of each variable was rounded to the nearest integer to assign a final score. Mental illness was rounded to 1 due to its clinical significance. The variables: number of medical issues and number of medications were grouped into four categories to simplify the scoring system. The tool was developed from a predictive model that identified nine key risk factors that were all significantly associated with increased odds of re-presentation to the ED. A fitted logistic regression equation of the form $\log [p /(1-p)]=-1.287+(\log O R$ Variable $)$ was applied to the nine key predictor variables to identify risk of representation among those who were homeless. ${ }^{32}$ The fitting of the model was performed using GenStat (8th edition, VSN International, UK) and because a patient may have repeated presentations to the ED the patient variable was fitted as a random effect in the model. A model was first fitted for each potential explanatory variable on its own. Variables for which the $P$-value for testing the hypothesis of no effect was greater than 0.05 were excluded from further model fitting. All the remaining explanatory variables were entered into a backwards stepwise procedure until all variables still in the model were significant at the 0.05 level. Significant twofactor interactions among these nine variables were then added to the model, but this did not improve prediction, so this more complicated model was not considered further.

The nine variables that significantly influenced representation of homeless people to the ED were: source of income (being a recipient of a government pension), age, next of kin documented, case management, presented to other hospitals within 12 months, primary illness, number of medications, number of medical issues and ED discharge outcome. Finally, these nine key variables identified as significant in the logistic regression model were converted into a scoring system utilised in the final risk screening tool (Fig. 1).

The electronic data for all patients $(n=40,492)$ and ED visits $(n=64,177)$ during a 24 -month study period (January 1, 2003 to December 31, 2004) were extracted from a single hospital site. ${ }^{31}$ The terms re-presentation, homelessness, and Australian Triage Scale (ATS) in this paper need to be defined. Rates of re-presentation, defined as the total number of visits to the same emergency department within 28 days of discharge from hospital, were calculated for the subgroups that were homeless. Four levels of homelessness were used based on Chamberlain's ${ }^{34,35}$ classification of housing status: 'Primary homelessness' included those who had reported living on the streets or in squats, 'Secondary homelessness' included people residing in crisis accommodation; 'Tertiary homelessness' included people living in boarding houses; 'Marginalised housing' included residing in public housing requiring rental assistance or those with other unstable rental arrangements. The Australasian Triage Scale (ATS) has been designed for use in hospital-based EDs throughout Australia ${ }^{36}$ and rates clinical urgency to ensure the person presenting to the ED is seen in a timely manner (Table 3). The inter-rater reliability was calculated and the kappa statistic for the risk of re-presentation was $0.81(95 \%$ $\mathrm{CI}$, 0.77-0.88) (Table 4).

\section{Prospective tool evaluation}

\section{Study design}

The prospective cohort design was conducted during a onemonth study period from April 1, 2009 to April 30, 2009, All ED visits involving people classified as homeless were included, excluding those who died during the study period.

\section{Methods of measurement}

Homelessness was defined as living on the streets, in crisis accommodation, in boarding houses or residing in unstable housing. Homelessness was identified by usual place of residence recorded on admission. Rates of re-presentation were defined as the total number of visits to the same emergency department within 28 days of discharge from hospital.

\section{Setting}

The study was conducted at an adult, tertiary referral hospital in an Australian city with a population of 3.9 million people. The annual ED attendance is approximately 40,000 . 
Table 2 Conversion of model coefficients into scoring of risk screening tool.

\begin{tabular}{|c|c|c|c|c|}
\hline Explanatory variable & Coefficient & $\times 10$ & Final score & \\
\hline \multicolumn{5}{|l|}{ Individual characteristics } \\
\hline \multicolumn{5}{|l|}{ Pensioner } \\
\hline No & Reference & 0 & 0 & \\
\hline Yes & 0.295 & 3 & 3 & \\
\hline \multicolumn{5}{|l|}{ Age } \\
\hline$>65$ years & Reference & 0 & 0 & \\
\hline$\leq 65$ years & 0.314 & 3 & 3 & \\
\hline \multicolumn{5}{|l|}{ Next of kin documented } \\
\hline No & Reference & 0 & 0 & \\
\hline Yes & 0.302 & 3 & 3 & \\
\hline \multicolumn{5}{|c|}{ Community case management } \\
\hline No & Reference & 0 & 0 & \\
\hline Yes & 0.267 & 3 & 3 & \\
\hline \multicolumn{5}{|l|}{ Presented to other hospital } \\
\hline No & Reference & 0 & 0 & \\
\hline Yes & 0.374 & 4 & 4 & \\
\hline \multicolumn{5}{|l|}{ Primary illness } \\
\hline Injury & Reference & 0 & 2 & \\
\hline Mental illness & 0.040 & 1 & 3 & \\
\hline Substance misuse & 0.096 & 1 & 3 & \\
\hline Medical/other & -0.208 & -2 & 0 & \\
\hline \multirow[t]{4}{*}{ Number of medications } & 0.034 & 3 per medication & 0 & $<5$ \\
\hline & & & 2 & $5-9$ \\
\hline & & & 4 & $10-14$ \\
\hline & & & 6 & $>14$ \\
\hline \multirow[t]{4}{*}{ Number of medical issues } & 0.061 & 6 per medical issue & 2 & $<4$ \\
\hline & & & 4 & $4-7$ \\
\hline & & & 6 & $8-10$ \\
\hline & & & 8 & $>10$ \\
\hline \multicolumn{5}{|l|}{ ED visit characteristics } \\
\hline \multicolumn{5}{|l|}{ Discharge outcome } \\
\hline Home & Reference & 0 & 3 & \\
\hline Transfer other facility & 0.199 & 2 & 5 & \\
\hline Left own risk & 0.267 & 3 & 6 & \\
\hline Admit & -0.285 & -3 & 0 & \\
\hline Residential care facility & 1.126 & 11 & 14 & \\
\hline Return to ward & -0.109 & -1 & 2 & \\
\hline ED admit & 0.134 & 1 & 4 & \\
\hline
\end{tabular}

When allocating a score for mental illness it scored between injury and substance misuse. It was decided to score mental illness as 1 in line with substance misuse.

The ED was served by an Admission, Liaison, Early Referral Team (ALERT), which provided care coordination to people who had complex care needs, such as homeless individuals.

\section{Study period}

All patients were screened consecutively on presentation to the ED during the one-month study period by clerical staff and the first author utilising the screening tool (Fig. 1) to determine housing status and hence eligibility for study follow-up. A flowchart was created to direct staff in the screening process (Fig. 2).

\section{Participants}

Once the patient was identified as homeless the screening tool was labelled, dated and given to ALERT or the first author who was blinded to the outcome measure of re-presentation at time of screening but may have been aware of patients' past record of ED presentations. The number of ED re-presentations within 28 days was subsequently collected by the researcher for each participant using the electronic patient administration system.

\section{Data analysis}

The logistic regression model developed for the homeless sample was converted into a scoring system for the risk screening tool. This process entailed converting the coefficients of the logistic regression model for the homeless sample through multiplying by 10 (to create 'user-friendly' scores) and adjusting the scoring to avoid negative-orientated scores. The scores in the components 
Table 3 Comparison of homeless and non-homeless populations in 2009.

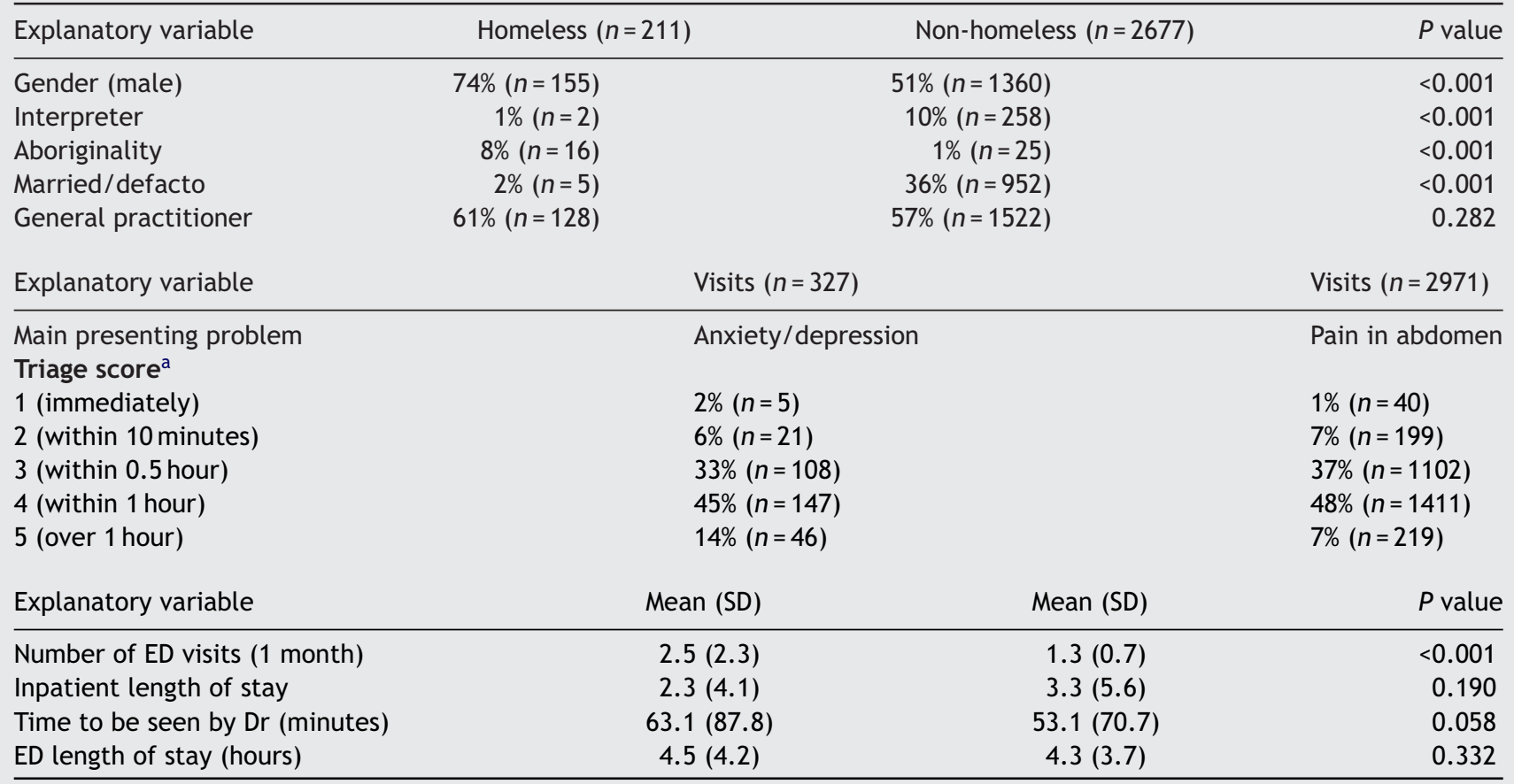

a Note: Australasian Triage Score. 1 (individual seen immediately), 2 (individual seen within 10 minutes), 3 (individual seen within 30 minutes), 4 (individual seen within 60 minutes) and 5 (individual seen within 120 minutes). $p=0.028$ for test of association between ordinal triage score and homelessness using gamma statistic.

Table 4 Kappa score for risk screening tool.

\begin{tabular}{lll}
\hline Explanatory variable & Kappa statistic & $95 \% \mathrm{Cl}$ \\
\hline Risk high/low & 0.81 & $0.77-0.88$ \\
Individual characteristics & & $0.84-0.95$ \\
Pensioner & 0.89 & $0.91-1.02$ \\
Age & 0.96 & $0.68-0.78$ \\
Next of kin documented & 0.74 & $0.52-0.62$ \\
Community case management & 0.56 & $0.60-0.72$ \\
Presented to other hospital & 0.66 & $0.38-0.47$ \\
Primary illness & 0.41 & $0.73-0.84$ \\
Number of medications & 0.79 & $0.49-0.58$ \\
Number of medical issues & 0.54 & \\
ED visit characteristics & & $0.59-0.65$ \\
Discharge outcome & 0.62 &
\end{tabular}

Table shows the scoring results by the 15 emergency nurses who reviewed 12 scenarios and rated them high/low risk for re-presentation to the ED. The scenario was rated high risk if the score was 14 or over. The kappa statistic for the risk of re-presentation was 0.81 ( $95 \%$ $\mathrm{Cl}, 0.77-0.88)$. This result shows very good inter-reliability. There was complete agreement for kappa scores obtained with eight of the scenarios.

of the tool were summed to create an overall score for each patient with a person identified as being at risk of re-presentation with a score of 14 or over. The final scores were used to calculate the sensitivity and specificity of the screening tool. The optimal cut-off was identified $(\geq 14, \geq 17$ and $\geq 19$ ) by comparing sensitivity, specificity, positive likelihood ratio (PLR), and negative likelihood ratio (NLR) (Fig. 3), and the accompanying ROC curve (Fig. 4), for a range of scores. Participants with an ED discharge outcome of death were excluded from the final analysis as this impacted on their re-presentation rate.

\section{Results}

The level of risk score ranged from six to twenty-nine with the mean $18.19(\mathrm{Cl}, 14-22)$. Three separate calculations of sensitivity and specificity were calculated using cut-off 


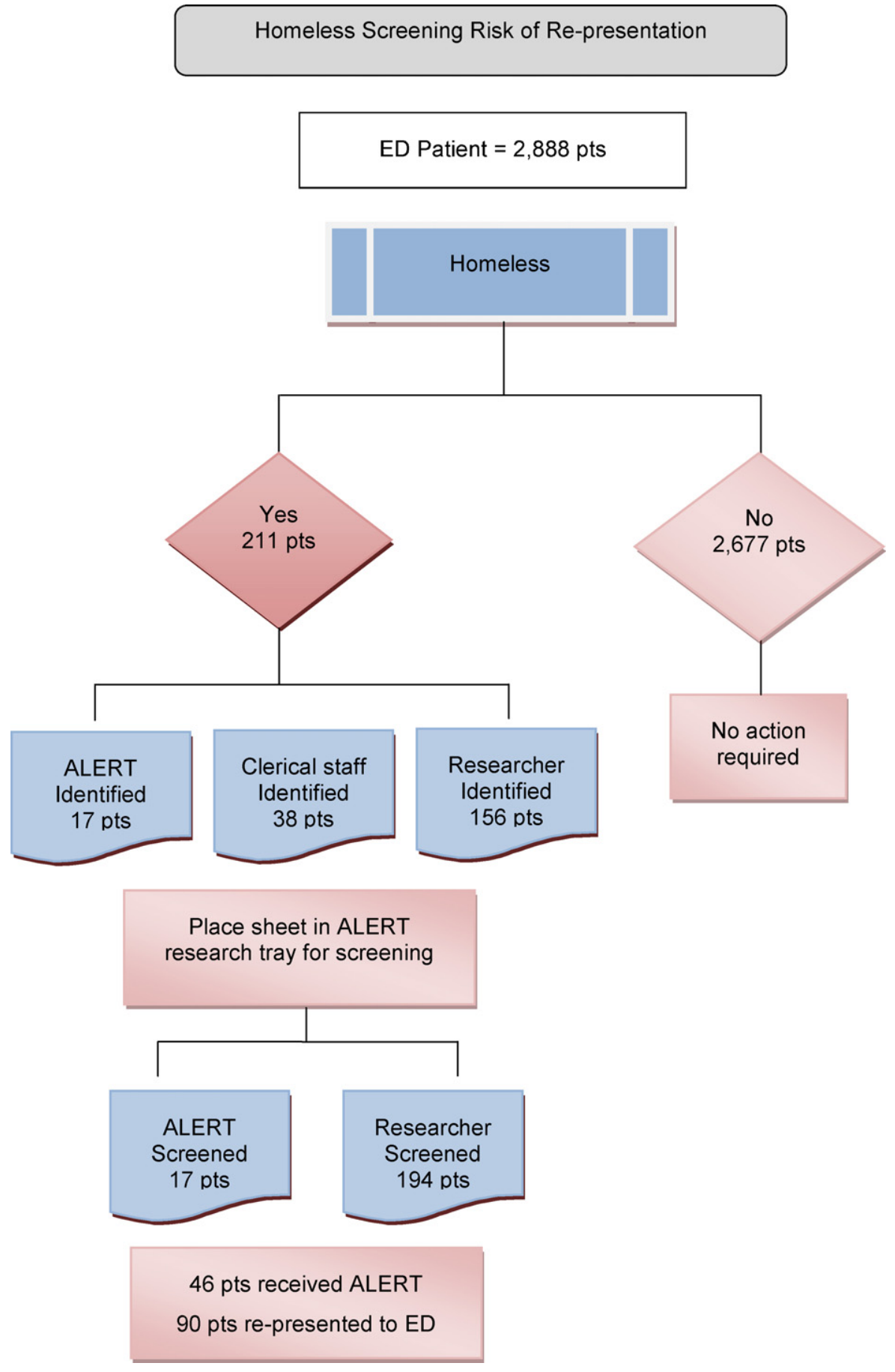

Figure 2 Flowchart of screening process.

scores for high risk of re- presentation as $\geq 14, \geq 17$ and $\geq 19$ (Fig. 3). A cut-off of $\geq 17$ yielded the best balance between sensitivity $98 \%(95 \% \mathrm{Cl}, 0.92-0.99)$ and specificity $66 \%$ (95\% $\mathrm{Cl}, 0.57-0.74)$ and resulted in an area under the ROC curve of $0.79(95 \% \mathrm{Cl}, 0.74-0.86)$, a PLR $2.9(95 \% \mathrm{Cl}, 2.2-3.7)$ and a NLR of $0.03(95 \% \mathrm{Cl}, 0.01-0.13)$. The PPV was $68 \%$ and represents the proportion of subjects with a positive test result who re-presented to ED. The NPV was $98 \%$ and represents the proportion of subjects with a negative test result who did not re-present to ED.
Over the one-month study period, 3298 ED presentations from 2888 individuals were recorded. The homeless population accounted for $10 \%(n=327)$ of all visits and $7 \%$ $(n=211)$ of all patients. A total of $90(43 \%)$ homeless people re-presented to the emergency department. Clerical staff identified 38 (18.0\%) homeless patients, ALERT identified and screened $17(8.1 \%)$ homeless patients and the first author identified and screened 156 (73.9\%) homeless patients. A careful review of the daily presentations to the ED by the first author ensured that no homeless person 


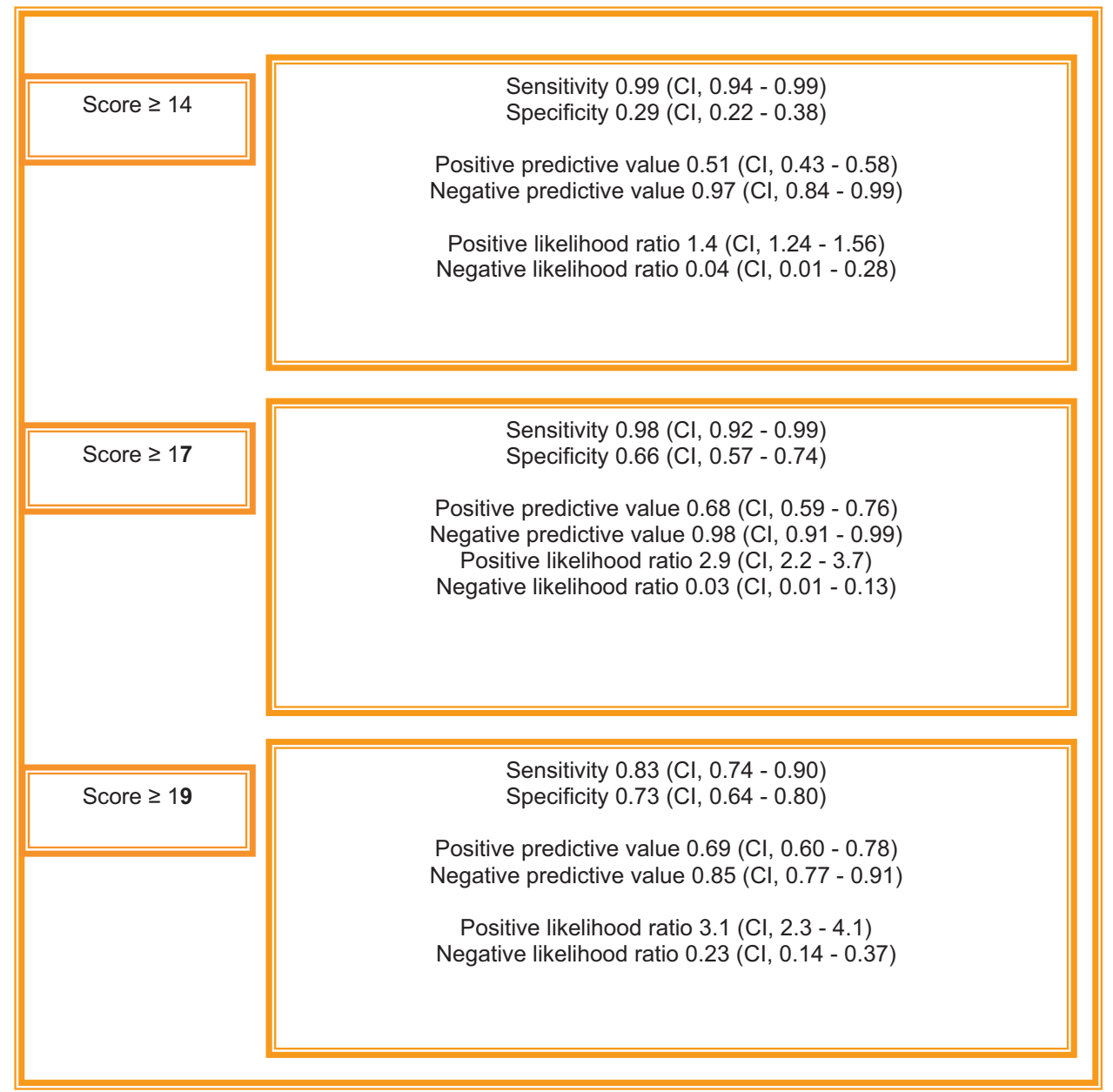

Figure 3 Sensitivity and specificity with positive and negative likelihood ratios. Note: The scoring is not a diagnostic screening to identify the presence of a disease but the need for referral and risk of re-presentation. The negative predictive value (NPV) is important to consider as an increase in referral to services when not needed adds additional stress to a service system already challenged to meet the needs of this complex group.

who presented to the ED over the study period was overlooked.

The current homeless population with data over one month (April 2009) used in this study was compared with the homeless population which spanned over 2 years $(2003 / 2004)$ and which was used to develop the risk screening tool (Table 5). ${ }^{29}$ The two homeless populations consisted of different people presenting to the ED. The 2009 homeless population represented $10 \%$ of the ED visits which was the same in the 2003/2004 homeless population. There was an increase in the percentage of homeless people who presented to the ED from $4 \%$ in $2003 / 2004$ to $7 \%$ in 2009 . The homeless population in 2009 had less complexity of illness and less drug and alcohol misuse. There was an increase in community case management from $31 \%$ in $2003 / 2004$ to $52 \%$ in 2009. There were fewer patients leaving at own risk and presenting to other hospitals in 2009.

Homeless patients differed significantly from nonhomeless patients according to gender, interpreter identified, aboriginality, married/defacto status, number of ED visits (within 1 month) and triage score. Compared to nonhomeless patients, there were twice as many homeless patients with a triage score of 5 on presentation to the ED (Table 3).

Sixty-seven (32\%) of the homeless patients who presented in the study period received case management or other intervention by ALERT. Of those homeless patients who were identified at risk of re-presentation $(\geq 17) 46$ (22\%) received an ALERT intervention. The intervention may have included a brief review of patient information on the computer system, information material on services, referral to subsequent services or a care coordination program. Thirty-three $(49 \%)$ of the homeless patients who received an intervention by ALERT re-presented to ED within 28 days post discharge. The remaining $144(68 \%)$ received standard ED care without referral or screening by ALERT.

\section{Discussion}

The predictive model was able to accurately identify the risk of re-presentation for those people who were homeless who presented to the ED during the study period. Risk screening tools are utilised in health care settings for many clinical 
Table 5 ED characteristics by Behavioural Model for homeless populations in 2003/2004 and 2009.

\begin{tabular}{|c|c|c|}
\hline Explanatory variable & $\begin{array}{l}2003 / 2004 \text { patient }(n=1595) \\
\text { Visit }(n=6689)\end{array}$ & $\begin{array}{l}2009 \text { patient }(n=211) \\
\text { Visit }(327)\end{array}$ \\
\hline \multicolumn{3}{|l|}{ Health behaviour } \\
\hline Re-presentation rate & $46 \%(n=735)$ & $43 \%(n=90)$ \\
\hline Left unseen own risk ${ }^{a}$ & $25 \%(n=403)$ & $14 \%(n=29)$ \\
\hline$\%$ homeless visits & $10 \%(n=6689)$ & $10 \%(n=327)$ \\
\hline Community case management ${ }^{a}$ & $31 \%(n=498)$ & $52 \%(n=109)$ \\
\hline After Hours & $76 \%(n=1219)$ & $57 \%(n=121)$ \\
\hline Presented to other hospital ${ }^{\mathrm{a}}$ (within 12 months) & $49 \%(n=777)$ & $30 \%(n=63)$ \\
\hline \multicolumn{3}{|l|}{ Environmental influences } \\
\hline$\%$ homeless population & $4 \%(1595 / 40,942)$ & $7 \%(211 / 2881)$ \\
\hline \multicolumn{3}{|l|}{ Level of homelessness } \\
\hline Primary & $23 \%(n=369)$ & $24 \%(n=51)$ \\
\hline Secondary & $16 \%(n=263)$ & $10 \%(n=21)$ \\
\hline Tertiary & $28 \%(n=441)$ & $33 \%(n=69)$ \\
\hline Marginalised & $33 \%(n=522)$ & $33 \%(n=70)$ \\
\hline Age 65 and under ${ }^{\mathrm{a}}$ & $85 \%(n=1354)$ & $89 \%(n=188)$ \\
\hline Male & $74 \%(n=1186)$ & $74 \%(n=155)$ \\
\hline Lived alone & $72 \%(n=1146)$ & $95 \%(n=201)$ \\
\hline Next of kin documented ${ }^{a}$ & $69 \%(n=1104)$ & $71 \%(n=149)$ \\
\hline Pensioner ${ }^{a}$ & $64 \%(n=1017)$ & $73 \%(n=153)$ \\
\hline Religious belief & $53 \%(n=842)$ & $50 \%(n=105)$ \\
\hline Country of birth (Australia) & $74 \%(n=1186)$ & $77 \%(n=164)$ \\
\hline \multicolumn{3}{|l|}{ Functional health status } \\
\hline Drug/alcohol misuse ${ }^{a}$ & $71 \%(n=1124)$ & $66 \%(n=139)$ \\
\hline Medical non-adherence & $63 \%(n=1001)$ & $64 \%(n=135)$ \\
\hline Dual diagnosis & $66 \%(n=1046)$ & $44 \%(n=93)$ \\
\hline \multicolumn{3}{|l|}{ Health status } \\
\hline Mental illness ${ }^{a}$ & $54 \%(n=861)$ & $55 \%(n=116)$ \\
\hline No. of medications $>3^{a}$ & $29 \%(n=465)$ & $18 \%(n=39)$ \\
\hline No. of medical illness $>3^{a}$ & $42 \%(n=664)$ & $27 \%(n=58)$ \\
\hline
\end{tabular}

a Indicates those variables that a part of the risk screening tool.

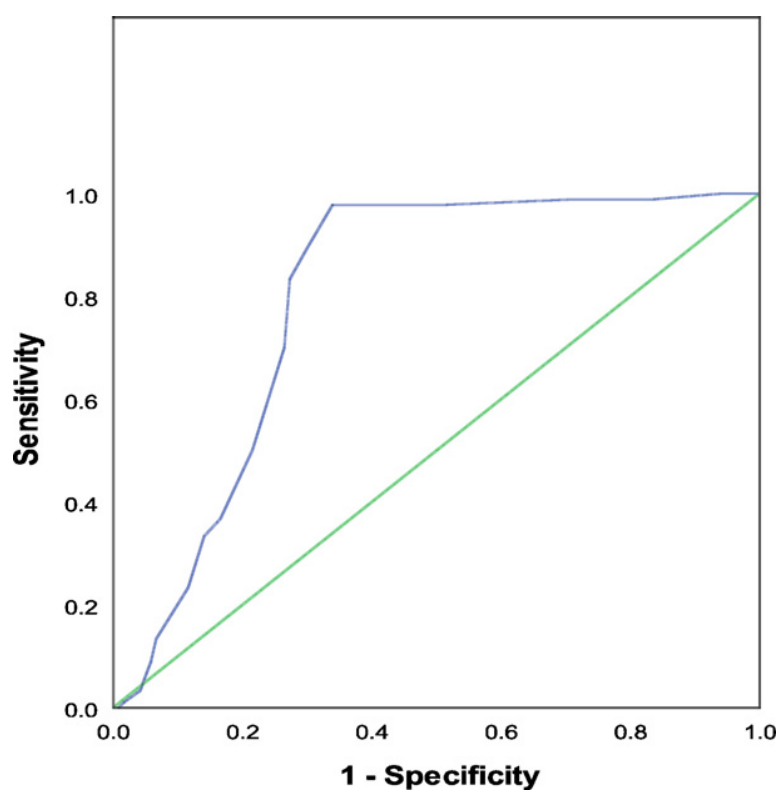

Figure 4 ROC curve of re-presentation (within 28 days) to emergency department by homeless people predicted by risk screening tool. Area under the curve (ROC) $0.797(\mathrm{Cl}$, $0.735-0.859)$. applications. The assumption that risk screening tools are better than clinical judgement and that they will be well utilised in the clinical setting are two main concepts that apply to all tools. The application and usability of the tool in the clinical setting will be the ultimate test no matter how reliably and validly the data are collected and researched.

Recommended strategies for implementing risk screening in practice emphasise the need for simplicity. ${ }^{37}$ Tools should contain at least five items and no more than 12 items. For the utility of screening tools in clinical practice, clinical experts undertaking the content validity exercise recommended that a tool should contain up to one page and the minimum of five items to maintain validity. This suggestion for brevity applies especially to the ED environment, which has a fast turnover of people and rapid treatment of those who are acutely ill. Screening tools are often used in the discharge process to ensure that key elements of health care are addressed either prior to discharge or implemented in the community. This risk screening tool was implemented on admission but it can also function as a guideline to the key care needs identified throughout the homeless person's hospital stay and then reviewed at discharge.

This research has taken into consideration key aspects of tool utilisation and developed a tool using a conceptual framework (Behavioural Model for Vulnerable Populations), 
research design (mixed methodology), data analysis (logistic regression, Kappa, sensitivity and specificity) and implementation strategies (future prospective study) to ensure a reliable and valid risk screening tool. The specific design of the tool has focused on making the tool easy to read and apply in the clinical setting without requiring additional information or extensive time for the clinicians.

A cut-off score of $\geq 17$ yielded the best balance between sensitivity $98 \%(95 \% \mathrm{Cl}, 0.92-0.99)$ and specificity $66 \%(95 \%$ $\mathrm{Cl}, 0.57-0.74)$. Adjusting the cut-off scoring was important to ensure the most accurate assessment of risk. Compromise had to be made and it was decided that sensitivity is more important than specificity in the context of this risk screening process. Early identification of those who will represent among homeless people is imperative in determining appropriate intervention. It was recognised that poor specificity could mean unnecessary resource allocation in an area already responding to high demand.

In the 2009 dataset there was an increase in the proportion of homeless people who presented to the ED which highlighted the problem of identifying homeless people with retrospective data. Even though extensive efforts were made to explore the 2003/4 ED presentation data $(n=64,177)$ it was difficult to identify all the homeless population (Table 5). The under enumeration in the 2003/2004 cohort may have resulted in the reduction of the percentage of mental illness and drug and/or alcohol misuse recorded in the 2009 homeless population. The non-homeless and homeless population in $\mathbf{2 0 0 9}$ were significantly different in gender, interpreter identified, aboriginality, marital status, number of ED visits (within 1 month) and triage score. These differences highlight the vulnerability and social isolation of the homeless population, who are more likely to live alone, and have decreased access to interpreters and general practitioners. Homeless people are more like to have less acuity with their major presenting problem as anxiety/depression.

The sensitivity, specificity, PLR, NLR and ROC curve calculated on the 2009 prospective data showed marked improvement from the original retrospective data which developed the variables in the screening tool. (The final risk screening tool from 2003/2004 data with the person identified as high risk with a score of 14 or more.) This cut-off score was chosen so that across all people, $75 \%$ sensitivity was achieved at 50\% specificity, ROC $0.66(\mathrm{Cl}, 0.61-0.71)$. It is hard to speculate on the reason for this improvement except that scoring patients prospectively included the clinicians' knowledge of the patients' previous history of re-presentation which may have biased the scoring. Further exploration of the variables currently in the screening tool may lead to including past history of re-presentation.

The definition of homelessness used in this study extended the common understanding of people living on the streets to include people who live in poor quality public housing with unstable rental arrangements. Although the understanding of what constitutes 'home' varies across countries and within different ethnic groups, the word 'homeless' in this study refers to a complex and very vulnerable group that spans, age, gender, ethnicity and family setting. The four-tiered definition of homelessness is challenged by the transient nature of homelessness and the shift between levels, and despite the ever changing housing circumstance people remain vulnerable due to their illness and psychosocial crises.

Within the current climate of increasing hospital demand there is a strong focus on supporting people in their own environment to manage their illness and prevent health crises, which require hospital presentation. Better coordinated supports are needed between the hospital and the community for people with complex needs to manage their health and social needs. ${ }^{38}$ It is the linking of services and coordinated care that are so important in providing support. Case management is a vital service response but for people who are re-presenting to the ED and especially after hours, there is a need for more than a '9-5' service. With the social isolation that comes with homelessness it is important not to limit the service access to working hours. ALERT services were extended to 21:30 after the 2003/2004 data collection which may have impacted on the decreased incidence of 'left without being seen', 'presenting to other hospitals' and an increase in 'community case management'. This has implications for the way we structure our services. Hospitals have an accepted 24-hour service profile but not so for other services. This structure creates a default response leading to hospital presentation, which is not necessarily driven by a medical condition. The public health and housing system has failed to meet the increasing complex care needs of people who are homeless are the ED remains the key point of contact.

\section{Strengths and limitations}

The study involved analysis of clinical audit data for presentations to the targeted hospital and it was not possible to identify those people who may have presented to other hospitals after attending the study hospital. This study was based in a single hospital site, which is located in a large Australian city with a population of 3.9 million people. While the study was conducted at a single inner-city ED in Australia, this work has the potential to be replicated in other Australian EDs. The Australian health care system is similar to the British and Canadian health care systems; therefore it may be possible to directly compare rates and patterns of ED re-presentation among those countries and utilise this screening tool.

The screen tool relied on an ED discharge variable, 'discharge outcome' to give the risk score of re-presentation within 28 days. This has implications for the timely identification and referral for people identified at risk. Further modification of the screening tool with the exclusion of 'discharge outcome' may overcome this but the accuracy of the risk screening tool will need to be further tested in other settings.

Unfortunately there was limited utilisation of the screening tool by the staff in the ED, with only $8.1 \% \quad(n=17)$ homeless patients were screened by ALERT. It is important that ED nurses engage in the process of screening people who are homeless and promote early identification and referral. To address the issue of screening in the ED it is possible with the mathematical formula of the logistic regression modelling to create a computer generated calculation of risk of re-presentation. Once the variables are entered into the database on presentation to the ED, the system can 
identify a person at risk of re-presentation and then initiate a planned referral response to the appropriate clinicians. The implementation and trial of this process for all people who present to the ED may initiate early identification of people at risk of re-presentation to the ED. To achieve this objective there will need to be a standardisation of triage data especially in the area of homeless categorisation.

\section{Conclusion}

A defined understanding of re-presentation and homeless status underpinned by a risk screening tool has clinical relevance to assist in early recognition of risk factors and targeting specific resources. This risk screening tool has the capacity to clearly identify key factors that highlight risk of re-presentation within 28 days. The utilisation of administrative data in conjunction with clinical data is an effective method to identify the risk of re-presentation in the homeless population. It is possible to expand the modelling of risk to other binary outcomes such as mortality and re-admission, increasing the ability of health services to monitor their performance and respond to key issues. Service provision for patients who not only have a medical condition but are homeless is complex. Unless a hospital system develops strategies for early recognition, utilising resources such as the risk screening tool, and referral with a broader definition of homelessness, patients will continue to re-present with unresolved issues that are not confined to their medical condition.

\section{Provenance and conflicts of interest}

Marie Gerdtz is a Deputy Editor of the Australasian Emergency Nursing Journal but had no role to play in the peer-review or editorial decision-making associated with this manuscript whatsoever. All other authors reported no conflicts of interest. This paper was not commissioned.

\section{Funding statement}

Financial support was provided through the Australian Research Council Linkage Project Scheme, project number: LP0453587. Financial support was also provided by Research Endowment Fund, St. Vincent's Health.

\section{Research ethics statement}

This paper reports the findings of a research study that adhered to the National Statement on the Conduct of Human Research by the Australian National Health and Medical Research Council and has been approved by the institutional review board of the participating hospital, the participating community based organisation that deals with the needs of homeless people, and the university.

\section{Authorship}

GM, EM, MG, MK, TW conceived and designed the study. GM, EM, MG and TW obtained research funding. TW and MK supervised the conduct of the trial and data collection. GM undertook recruitment of patients and managed the data and analysis, including quality control. GH and DD provided statistical advice on study design and reviewed analysis. GM drafted the manuscript, and all authors contributed substantially to its revision. GM takes responsibility for the paper as a whole.

\section{References}

1. Plumb JD. Homelessness: reducing health disparities. CMAJ 2000;163(2):172-3.

2. Hargrave C. Homelessness in Canada. Nanaimo: Share International; 2004 [26.01.05].

3. Hwang S. Homelessness and health. CMAJ 2001;164(2):229.

4. D'Amore J, Hung $\mathrm{O}$, Chiang W, Goldfrank L. The epidemiology of the homeless population and Its impact on an urban emergency department. Acad Emerg Med 2001;8(11):1051-5.

5. Morris D, Gordon J. The role of the emergency department in the care of homeless and disadvantaged populations. Emerg Med Clin North Am 2006;24(4):839-48.

6. Phillips G, Brophy D, Weiland T, Chenhall A, Dent A. The effect of multidisciplinary case management on selected outcomes for frequent attenders at an emergency department. Med J Aust 2006;184:602-6.

7. Spillane L, Lumb E, Cobaugh D, Wilcox S, Clark J, Schneider S. Frequent users of the emergency department: can we intervene? Acad Emerg Med 1997;4(6):574-80.

8. Malone RE. Heavy users of emergency services: social construction of a policy problem. Soc Sci Med 1995;40(4):469-77.

9. Mandelberg JH, Kuhn RE, Kohn MA. Epidemiologic analysis of an urban public emergency department's frequent users. Acad Emerg Med 2000;7(6):637-46.

10. Ruger JP, Richter CJ, Spitznagel EL, Lewis LM. Analysis of costs, length of stay, and utilisation of emergency department services by frequent users: implications for health policy. Acad Emerg Med 2004;11(12):1311-7.

11. Zoot CJ, Moore FD. High-cost users of medical care. New Engl J Med 1980;302(18):996-1002.

12. Baker D, Stevens C, Brook R. Regular source of ambulatory care and medical utilization by patients presenting to a public emergency department. JAMA 1994;271(24):1909-12.

13. Stern R, Weissman P, Epstein A. The emergency department as a pathway to admission for poor and high cost patients. JAMA 1991;226(16):238-43.

14. Richardson LD, Hwang U. Access to care: a review of the emergency medicine literature. Acad Emerg Med 2001;8(11): 1030-6.

15. Dwyer J, Jackson T. Literature review: integrated bed and patient management. Melbourne: Victorian Department of Human Services; 2001, www.health.vic.gov.au/emergency/ bgdocs/litrview.pdf.

16. Fulde GW, Duffy M. Emergency department frequent flyers: unnecessary load or lifeline? Med J Aust 2006;184(12):595.

17. Murphy AW. Inappropriate attenders at accident and emergency departments. 1. Definition, incidence and reasons for attendance. Fam Pract 1998;15(1):23-31.

18. Lang T, Davido A, Diakité B, Agay E, Viel JF, Flicoteaux B. Using the hospital emergency department as a regular source of care. Eur J Epidemiol 1997;13(2):223-8.

19. Malone RE. Whither the almshouse? Overutilisation and the role of the emergency department. J Health Polit Polic Law 1998;23(5):795-832.

20. Chan D, Chong KR, Basilikas J, Mathie M, Hung WT. Survey of major chronic illnesses and hospital admissions via the emergency department in a randomised older population in Randwick, Australia. Emerg Med 2002;14:387-92. 
21. Dent A, Phillips G, Chenhall A, McGregor L. The heaviest repeat users of an inner city emergency department are not general practice patients. Emerg Med 2003;15(4):322-9.

22. Olsson $M$, Hansagi $H$. Repeated use of the emergency department: qualitative study of the patient's perspective. Emerg Med J 2001;18(6):430-4.

23. Moss J, Flower C, Houghton L, Moss D, Nielsen D, Taylor D. A multidisciplinary Care Coordination Team improves emergency department discharge planning practice. Med J Aust 2002;177(8):435-9.

24. Pope D, Fernandes C, Bouthillette F, Etherington J. Frequent users of the emergency department: a program to improve care and reduce visits. CMAJ 2000;4(7):162.

25. Kushel M, Perry S, Bangsberg D, Clark R, Moss A. Emergency department use among the homeless and marginally housed: results from a community-based study. Am J Public Health 2002;92(5):778.

26. Byrne M, Plunkett P, McGee H, Murray A, Bury G. Frequent attenders to an emergency department: a study of primary health care use, medical profile, and psycho-social characteristics. Ann Emerg Med 2003;41(3):309-18.

27. Salazar A, Bardes I, Juan A, Olonoa N, Sabida M, Corbella X. High mortality rates from medical problems of frequent emergency department users at a university hospital tertiary care centre. Eur J Emerg Med 2005;12:2-5.

28. Bergh H, Baigi A, Marklund B. Consultations for injuries by frequent attenders are found to be medically appropriate from a general practitioners' perspective. Scand J Public Health 2005;33(3):228-32.

29. Moore G, Gerdtz MF, Manias E, et al. Socio-demographic and clinical characteristics of re-presentation to an Australian inner city emergency department: implications for service delivery. BMC Public Health 2007;7, doi:10.1186/1471-2458-1187-1320.

30. McCusker J, Bellavance F, Cardin S, et al. Prediction of hospital utilization among elderly patients during the 6 months after an emergency department visit. Ann Emerg Med 2000;36: 438-45.

31. McCusker J, Bellavance F, Cardin S, et al. Detection of older people at increased risk of adverse health outcomes after an emergency visit: The ISAR screening tool. J Am Geriatr Soc 1999;47:1229-37.

32. Moore G, Gerdtz MF, Hepworth G, et al. Homelessness: patterns of emergency department use and risk factors for re-presentation. Emerg Med J 2010, doi:10.1136/emj.2009.087239.

33. Gelberg L, Andersen RM, Leake BD. The Behavioral Model for Vulnerable Populations: application to medical care use and outcomes for homeless people. Health Serv Res 2000;34(6):1273-302.

34. Chamberlain C, Mackenzie D. Counting the homeless. Commonwealth of Australia: Australian Bureau of Statistics; 2001.

35. Chamberlain C, MacKenzie D. Counting the homeless. Commonwealth of Australia: Australian Bureau of Statistics; 2006.

36. Australasian College for Emergency Medicine. Policy on the Australasian Triage Scale. Melbourne; 2000.

37. Jacobson S. Evaluating instruments for use in clinical nursing research. In: Frank-Stranborg, Jacobson S, editors. Instruments for clinical health-care research. 3rd ed. Sudbury, MA: Jones \& Bartlett; 2004.

38. Gronda $\mathrm{H}$. What makes case management work for people experiencing homelessness? Evidence for practice, AHURI final report no. $127 ; 2009$. 